\title{
New Paradigm for Studying Genetic Contributions to Irritable Bowel Syndrome
}

\author{
Miranda A. L. van Tilburg • William E. Whitehead
}

Published online: 29 August 2012

(C) Springer Science+Business Media, LLC 2012

Irritable Bowel Syndrome (IBS) is common disabling condition that is associated with an estimated $\$ 8$ billion per year in direct healthcare costs [1]. In the past few decades multiple studies have been published on the etiology of IBS, and several pathophysiological factors have been found to be significantly associated with IBS diagnosis, such as motility disturbances, visceral hypersensitivity, psychological distress, and immune dysregulation. However, none of these factors is sufficient by itself to explain the development of IBS. Therefore, it is widely believed that IBS is not caused by a single factor but rather the interaction of various biological, psychological, and social factors which interact to contribute to the etiology and maintenance of the disorder [2]. No single factor appears to be necessary for disease expression, and none may be sufficient in isolation from the others.

Considering this complex model of the causes of IBS, it is no surprise that genetic factors in IBS generally are not expected to follow a Mendelian inheritance pattern in which the disease is caused by a single gene [3-5]. Rather, it is thought that IBS is a complex genetic disorder with genes affecting the various etiological factors described above. It is, therefore, reasonable to expect that this complex model of IBS involving interactions between physiological vulnerabilities and psychosocial stressors will be matched at the molecular level by gene-gene and geneenvironment interactions. The study by Saito et al. [6] in this issue of Digestive Diseases and Sciences is significant

M. A. L. van Tilburg $(\bowtie) \cdot$ W. E. Whitehead

Center for Functional GI and Motility Disorders, University of North Carolina at Chapel Hill, 4106 Bioinformatics Building,

130 Mason Farm Rd, Campus Box 7080, Chapel Hill, NC 27599-7080, USA

e-mail: Tilburg@med.unc.edu because it demonstrates that taking these interactions into account can unmask genetic contributions to IBS etiology where simple genetic association studies have failed to show an effect. This is the second study to show that a genetic polymorphism interacts with exposure to infectious gastroenteritis to contribute to the expression of postinfectious IBS; the first was the study by Villani et al. [7] which found that polymorphisms in Toll-like receptor 9, interleukin (IL)-6, and CDH1 were associated with an increased likelihood of the reporting of persistent gastrointestinal symptoms following exposure to a water-borne outbreak of gastroenteritis. These polymorphisms were not found to be associated with IBS developing in the absence of gastroenteritis [8]. These two studies likely herald a turning point in the evolution of studies on the genetic contributions to IBS and other complex diseases. This paradigm shift offers the promise of more precise estimates of disease prediction, provides greater insights into gene function, and, by suggesting how to ameliorate the impact of genetic risk, offers the potential of greater clinical impact.

The article by Saito and colleagues also points out the challenges in carrying out investigations of gene-environment interactions: such studies need to be hypothesis driven because the possible permutations of genetic polymorphisms and environmental exposures are nearly infinite. Several candidate gene studies have been associated with IBS [3-5]. These include, among others, serotonin receptor and transporter genes [9-17], adrenoreceptor genes [18-22], and genes in the inflammatory pathway [7, 8, 23-25]. In addition, multiple environmental factors have been shown to play a role in IBS, such as an affluent childhood, early infant trauma (e.g., gastric suction at birth, low birth weight, and severe nutritional deficits), sexual or physical abuse history, life stress, military deployment, 
social learning, and gastroenteritis [26-31]. Gene studies should carefully explore the interactions of these environmental effects and polymorphisms in IBS. In identifying an a priori hypothesis, a clear rationale is needed that links the gene's presumed function to one of the endophenotypes believed to explain the symptoms of IBS (e.g., pain hypersensitivity, stress reactivity, immune dysregulation), and an environmental exposure that is already known to be associated with this endophenotype. In the Saito study, the authors focused on a possible association between 5HTTLPR and a history of abuse based on previous evidence that this polymorphism is linked to the development of psychiatric disorders in the presence of an abuse history [32], but they did not find support for this gene-environment interaction in IBS. They based their second hypothesis of an interaction between the GNbeta3 polymorphism and a history of gastroenteritis on previous evidence that GNbeta3 is involved in immune regulation, and their hypothesis was supported. However, there are other genetic markers more closely associated with impaired immune function in IBS, such as IL-10 [23], which might have been more logical than GNbeta3 to test for their interaction with prior gastroenteritis. The authors do not explain their preference for GNbeta3 over these other genes.

Other well-known limitations to IBS genetic association studies also apply to studies of gene-environment interactions: (1) the IBS phenotype is imprecise because it is based on symptoms ascertained by self-report and a negative medical work-up, which may lead to heterogeneity in the samples studied; (2) validated, objective measures of environmental exposures and prospective research designs are preferable to chart reviews and retrospective self-report to protect against measurement error. With these limitations in mind, replication of findings by independent investigators will continue to be necessary to move this field forward.

Thus, for IBS, multiple genes likely contribute in an additive or synergistic fashion and critical environmental exposures interact with these genetic risk factors to trigger expression of the disease phenotype only if the environmental exposure is present. To date, up to 60 candidate genes have been identified in IBS [33], although few have been independently replicated. Researchers are therefore at an exciting crossroads where the use of complex models that include genes, endophenotypes, and environmental factors may start facilitating the elucidation of important pathways for this enigmatic disorder. For example, the 5HTTLPR (gene) has been associated with higher rectal pain ratings [34], anxiety, and depression [35] in IBS patients (endophenotype), and interacts with stressful life events in the expression of major depression (a possible environmental factor) [36]. Studies combing these factors into one model are greatly needed to unravel the mystery of IBS etiology and develop more personalized treatment models.
Acknowledgments Supported in part by grant R01DK031369 from NIDDK and P01NS045685 from NINDS.

\section{References}

1. Talley NJ, Gabriel SE, Harmsen WS, et al. Medical costs in community subjects with irritable bowel syndrome. Gastroenterology. 1995;109:1736-1741.

2. Drossman DA. Presidential address: gastrointestinal illness and the biopsychosocial model. Psychosom Med. 1998;60:258-267.

3. Saito YA, Mitra N, Mayer EA. Genetic approaches to functional gastrointestinal disorders. Gastroenterology. 2010;138:1276-1285.

4. Fukudo S, Kanazawa M. Gene, environment, and brain-gut interactions in irritable bowel syndrome. J Gastroenterol Hepatol. 2011;26:110-115.

5. Camilleri M, Katzka DA. Irritable bowel syndrome: methods, mechanisms, and pathophysiology. Genetic epidemiology and pharmacogenetics in irritable bowel syndrome. Am J Physiol Gastrointest Liver Physiol. 2012;302:G1075-G1084.

6. Saito YA, Larson JJ, Atkinson EJ, et al. The role of 5-HTT LPR and GNbeta3 $825 \mathrm{C}>\mathrm{T}$ polymorphisms and gene-environment interactions in irritable bowel syndrome. Dig Dis Sci. 2012 [Epub ahead of print]. doi:10.1007/s10620-012-2319-9.

7. Villani AC, Lemire M, Thabane M, et al. Genetic risk factors for postinfectious irritable bowel syndrome following a waterborne outbreak of gastroenteritis. Gastroenterology. 2010;138:1502-1513.

8. Villani AC, Saito YA, Lemire M. Validation of genetic risk factors for post-infectious irritable bowel syndrome (IBS) in patients with sporadic IBS. Gastroenterology. 2009;136:289.

9. Pata C, Erdal ME, Derici E, et al. Serotonin transporter gene polymorphism in irritable bowel syndrome. Am J Gastroenterol. 2002;97:1780-1784.

10. Camilleri M, Atanasova E, Carlson PJ, et al. Serotonin-transporter polymorphism pharmacogenetics in diarrhea-predominant irritable bowel syndrome. Gastroenterology. 2002;123:425-432.

11. Yeo A, Boyd P, Lumsden S, et al. Association between a functional polymorphism in the serotonin transporter gene and diarrhoea predominant irritable bowel syndrome in women. Gut. 2004;53:1452-1458.

12. Li Y, Nie Y, Xie J, et al. The association of serotonin transporter genetic polymorphisms and irritable bowel syndrome and its influence on tegaserod treatment in Chinese patients. Dig Dis Sci. 2007;52:2942-2949.

13. Sikander A, Rana SV, Prasad KK. Role of serotonin in gastrointestinal motility and irritable bowel syndrome. Clin Chim Acta. 2009;403:47-55.

14. Niesler B, Kapeller J, Fell C, et al. 5-HTTLPR and STin2 polymorphisms in the serotonin transporter gene and irritable bowel syndrome: effect of bowel habit and sex. Eur J Gastroenterol Hepatol. 2010;22:856-861.

15. Jarrett ME, Kohen R, Cain KC, et al. Relationship of SERT polymorphisms to depressive and anxiety symptoms in irritable bowel syndrome. Biol Res Nurs. 2007;9:161-169.

16. Pata C, Erdal E, Yazc K, et al. Association of the -1438 G/A and $102 \mathrm{~T} / \mathrm{C}$ polymorphism of the 5-Ht2A receptor gene with irritable bowel syndrome 5-Ht2A gene polymorphism in irritable bowel syndrome. J Clin Gastroenterol. 2004;38:561-566.

17. Markoutsaki T, Karantanos T, Gazouli M, et al. 5-HT2A receptor gene polymorphisms and irritable bowel syndrome. J Clin Gastroenterol. 2011;45:514-517.

18. Kim HJ, Camilleri M, Carlson PJ, et al. Association of distinct alpha(2) adrenoceptor and serotonin transporter polymorphisms with constipation and somatic symptoms in functional gastrointestinal disorders. Gut. 2004;53:829-837. 
19. Holtmann G, Siffert W, Haag S, et al. G-protein beta 3 subunit $825 \mathrm{CC}$ genotype is associated with unexplained (functional) dyspepsia. Gastroenterology. 2004;126:971-979.

20. Grudell AB, Camilleri M, Carlson P, et al. An exploratory study of the association of adrenergic and serotonergic genotype and gastrointestinal motor functions. Neurogastroenterol Motil. 2008;20:213-219.

21. Sikander A, Rana SV, Sharma SK, et al. Association of alpha $2 \mathrm{~A}$ adrenergic receptor gene (ADRAlpha2A) polymorphism with irritable bowel syndrome, microscopic and ulcerative colitis. Clin Chim Acta. 2010;411:59-63.

22. Onodera S, Chiba T, Sugai T, et al. A genetic association between ss3-aderenoceptor and cholinergic receptor muscarinic 3 polymorphisms in irritable bowel syndrome. Hepatogastroenterology. 2011;58:1474-1478.

23. Gonsalkorale WM, Perrey C, Pravica V, et al. Interleukin 10 genotypes in irritable bowel syndrome: evidence for an inflammatory component? Gut. 2003;52:91-93.

24. van der Veek PJ, van den Berg M, de Kroon YE, et al. Role of tumor necrosis factor-alpha and interleukin-10 gene polymorphisms in irritable bowel syndrome. Am $J$ Gastroenterol. 2005;100:2510-2516.

25. Zucchelli M, Camilleri M, Andreasson AN, et al. Association of TNFSF15 polymorphism with irritable bowel syndrome. Gut. 2011;60:1671-1677.

26. Chitkara DK, van Tilburg MA, Blois-Martin N, et al. Early life risk factors that contribute to irritable bowel syndrome in adults: a systematic review. Am J Gastroenterol. 2008;103:765-774.

27. Klooker TK, Braak B, Painter RC, et al. Exposure to severe wartime conditions in early life is associated with an increased risk of irritable bowel syndrome: a population-based cohort study. Am J Gastroenterol. 2009;104:2250-2256.

28. Gray GC, Reed RJ, Kaiser KS, et al. Self-reported symptoms and medical conditions among 11,868 Gulf War-era veterans: the Seabee Health Study. Am J Epidemiol. 2002;155:1033-1044.

29. Leserman J, Drossman DA. Relationship of abuse history to functional gastrointestinal disorders and symptoms: some possible mediating mechanisms. Trauma Violence Abuse. 2007;8:331-343.

30. Levy RL, Langer SL, Whitehead WE. Social learning contributions to the etiology and treatment of functional abdominal pain and inflammatory bowel disease in children and adults. World $J$ Gastroenterol. 2007;13:2397-2403.

31. Spiller R, Garsed K. Infection, inflammation, and the irritable bowel syndrome. Dig Liver Dis. 2009;41:844-849.

32. Brown GW, Harris TO. Depression and the serotonin transporter 5-HTTLPR polymorphism: a review and a hypothesis concerning gene-environment interaction. J Affect Disord. 2008;111:1-12.

33. Saito YA. The role of genetics in IBS. Gastroenterol Clin North Am. 2011;40:45-67.

34. Camilleri M, Busciglio I, Carlson P, et al. Candidate genes and sensory functions in health and irritable bowel syndrome. Am J Physiol Gastrointest Liver Physiol. 2008;295:G219-G225.

35. Mizuno T, Aoki M, Shimada Y, et al. Gender difference in association between polymorphism of serotonin transporter gene regulatory region and anxiety. J Psychosom Res. 2006;60:91-97.

36. Caspi A, Sugden K, Moffitt TE, et al. Influence of life stress on depression: moderation by a polymorphism in the 5-HTT gene. Science. 2003;301:386-389. 